\title{
Antioxidant Systems are Regulated by Nitric Oxide-Mediated Post-translational Modifications (NO-PTMs)
}

Juan C. Begara-Morales ${ }^{1}$, Beatriz Sánchez-Calvo' ${ }^{1}$ Mounira Chaki ${ }^{1}$,

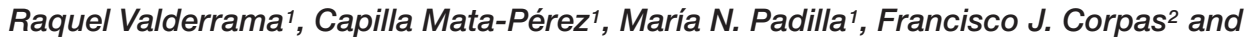
Juan B. Barroso ${ }^{1 *}$

${ }^{1}$ Group of Biochemistry and Cell Signaling in Nitric Oxide, Department of Experimental Biology, Center for Advanced Studies in Olive Grove and Olive Oils, Faculty of Experimental Sciences, University of Jaén, Jaén, Spain, ${ }^{2}$ Group of Antioxidants, Free Radicals and Nitric Oxide in Biotechnology, Food and Agriculture, Department of Biochemistry, Cellular and Molecular Biology of Plants, Estación Experimental del Zaidín, Consejo Superior de Investigaciones Cientificas, Granada, Spain

OPEN ACCESS

Edited by:

Violeta Velikova,

Bulgarian Academy of Sciences Institute of Plant Physiology

and Genetics, Bulgaria

Reviewed by:

Georgia Tanou,

Aristotle University of Thessalonik,

Greece

Nan Yao,

Sun Yat-Sen University, China

*Correspondence:

Juan B. Barroso

jbarroso@ujaen.es

Specialty section: This article was submitted to Plant Biotic Interactions, a section of the journal

Frontiers in Plant Science

Received: 24 November 2015

Accepted: 29 January 2016

Published: 16 February 2016

Citation:

Begara-Morales JC, Sánchez-Calvo B, Chaki M, Valderrama R, Mata-Pérez C,

Padilla MN, Corpas FJ and Barroso JB (2016) Antioxidant

Systems are Regulated by Nitric Oxide-Mediated Post-translational

Modifications (NO-PTMS)

Front. Plant Sci. 7:152.

doi: 10.3389/fpls.2016.00152
Nitric oxide (NO) is a biological messenger that orchestrates a plethora of plant functions, mainly through post-translational modifications (PTMs) such as S-nitrosylation or tyrosine nitration. In plants, hundreds of proteins have been identified as potential targets of these NO-PTMs under physiological and stress conditions indicating the relevance of $\mathrm{NO}$ in plant-signaling mechanisms. Among these $\mathrm{NO}$ protein targets, there are different antioxidant enzymes involved in the control of reactive oxygen species (ROS), such as $\mathrm{H}_{2} \mathrm{O}_{2}$, which is also a signal molecule. This highlights the close relationship between ROS/NO signaling pathways. The major plant antioxidant enzymes, including catalase, superoxide dismutases (SODs) peroxiredoxins ( $\operatorname{Prx}$ ) and all the enzymatic components of the ascorbate-glutathione (Asa-GSH) cycle, have been shown to be modulated to different degrees by NO-PTMs. This mini-review will update the recent knowledge concerning the interaction of $\mathrm{NO}$ with these antioxidant enzymes, with a special focus on the components of the Asa-GSH cycle and their physiological relevance.

Keywords: ascorbate-glutathione cycle, catalase, superoxide dismutase, peroxiredoxin, nitric oxide, $S$-nitrosylation, tyrosine nitration

\section{INTRODUCTION}

Nitric oxide is a gaseous molecule and a pivotal biological messenger. NO is involved in signaling pathways that are related to fundamental processes in plant biology such as growth and development (Beligni and Lamattina, 2000; Pagnussat et al., 2002), senescence (Begara-Morales et al., 2013) and response to abiotic (Corpas et al., 2011; Siddiqui et al., 2011) or biotic stress (Delledonne et al., 1998; Durner et al., 1998; Feechan et al., 2005). Generally, the rise in NO levels in response to stress conditions is accompanied by another group of molecules called reactive oxygen species (ROS), some of which, particularly $\mathrm{H}_{2} \mathrm{O}_{2}$, are also involved in multiple signaling pathways

Abbreviations: Asa-GSH cycle, ascorbate-glutathione cycle; APX, ascorbate peroxidase; DHAR, dehydroascorbate reductase; GR, glutathione reductase; MDAR, monodehydroascorbate reductase; NO-PTMs, nitric oxide-related posttranslational modifications. 
(Neill et al., 2002). This mini-review will explore recent findings concerning the modulation of the main antioxidant enzymes by $\mathrm{NO}$, especially the enzymatic components of Asa-GSH cycle, with particular attention to the molecular mechanism underpinning this key regulatory pathway in response to stress situations.

\section{NITRIC OXIDE-MEDIATED POST-TRANSLATIONAL MODIFICATIONS: NITRATION AND S-NITROSYLATION}

Nitric oxide mainly transmits its action via post-translational modifications, such as $S$-nitrosylation and tyrosine nitration, which can regulate the function of the target proteins (Astier and Lindermayr, 2012). These NO-PTMs may be involved in cell signaling under physiological and stress conditions (Corpas et al., 2015).

Tyrosine nitration, which is mediated mainly by peroxynitrite $\left(\mathrm{ONOO}^{-}\right)$, consists of the addition of $\mathrm{NO}_{2}$ radicals to one of the two equivalent ortho-carbons of the aromatic ring of tyrosine residues leading to 3-nitrotyrosine (Gow et al., 2004; Radi, 2004). This modification converts the tyrosine into a negatively charged residue and causes a marked shift in the hydroxyl group's pKa (Turko and Murad, 2002; Abello et al., 2009) which can affect the target proteins resulting in a gain, loss or no change in the protein's function (Souza et al., 2008; Radi, 2013). Although tyrosine nitration has been traditionally considered as an irreversible mechanism and a nitrosative stress marker, the existence of tyrosine denitrase activity that reduces 3-nitrotyrosine in mammalian cells (Görg et al., 2007; Deeb et al., 2013) pointing toward a role of tyrosine nitration in NO-mediated signaling processes in these cells.

$S$-nitrosylation consists of the addition of a NO group to a cysteine thiol leading to $S$-nitrosothiols (SNOs) and consequently can also alter the function of a broad variety of proteins (Hess et al., 2005; Astier et al., 2011). S-nitrosoglutathione (GSNO), formed by $S$-nitrosylation of the antioxidant GSH, is the major low-molecular-weight $S$-nitrosothiol. It is considered to be a NO reservoir in cells (Gaston et al., 1993; Durner et al., 1999; Leitner et al., 2009) that due to its phloem mobility is involved in signaling mechanisms. Furthermore, GSNO can mediate transnitrosylation reactions in which a new $S$-nitrosothiol is generated by transferring its NO group to a new cysteine thiol group (Hess et al., 2005).

$S$-nitrosylation is a reversible mechanism since SNO can be specifically and enzymatically broken down by thioredoxins (Benhar et al., 2008; Kneeshaw et al., 2014), in addition to the non-enzymatic decomposition by antioxidants such as ascorbate or glutathione. Furthermore, $S$-nitrosoglutathione reductase (GSNOR) decomposes GSNO and indirectly controls SNO levels (Liu et al., 2001; Feechan et al., 2005).

In recent years, mounting evidence has shown that SNOs are fundamental players in NO-signaling pathways in plant biology (Belenghi et al., 2007; Romero-Puertas et al., 2007, 2008; Lindermayr and Durner, 2009; Astier et al., 2011; Hu et al., 2015), with an important role in plant immunity and plant response to abiotic stresses (Feechan et al., 2005; Rusterucci et al., 2007; Valderrama et al., 2007; Corpas et al., 2008; Chaki et al., 2009a, 2011a,b). Due to its importance, increased efforts have been made to identify the processes that could be regulated by SNOs and subsequently hundreds of proteins that undergo $S$-nitrosylation under physiological or adverse conditions have been identified over the past decade.

\section{S-NITROSYLATION CONTROLS ONOO- LEVELS VIA REGULATION OF PrXII E}

Peroxiredoxins (Prx) are thiol based peroxidases that can be involved in multiple functions in addition to its role in detoxifying $\mathrm{H}_{2} \mathrm{O}_{2}$ (for review see Bhatt and Tripathi, 2011). Some Prxs have been identified to be regulated by NO-PTMs in animals and plants. In mammals, $S$-nitrosylation inhibits the enzymatic activity of neuronal Prx2 (Fang et al., 2007) and Prx1 (Engelman et al., 2013) whereas the peroxidase activity of Prx2 from mammalian erythrocytes was induced after tyrosine nitration (Randall et al., 2014). In plants, S-nitrosylation inhibits the peroxidase activity of PrxII E (Romero-Puertas et al., 2007) and PrxII F (Camejo et al., 2015). Interestingly, some members of Prx family posses $\mathrm{ONOO}^{-}$reductase activity (Bryk et al., 2000; Romero-Puertas et al., 2007; Pedrajas et al., 2010) and therefore could protect against $\mathrm{ONOO}^{-}$-mediated oxidative and nitrosative stresses. In plants, PrxII E is $S$-nitrosylated during hypersensitive response (Romero-Puertas et al., 2008) and this modification inhibits its peroxynitrite reductase activity promoting tyrosine nitration (Romero-Puertas et al., 2007). Therefore, S-nitrosylation emerges as a key mechanism in $\mathrm{ONOO}^{-}$homeostasis, regulating endogenous level of $\mathrm{ONOO}^{-}$ and tyrosine nitration via control of PrxII E (Romero-Puertas et al., 2007). Changes in $\mathrm{ONOO}^{-}$levels and/or tyrosine nitration have been related to several abiotic/biotic stresses (Valderrama et al., 2007; Corpas et al., 2008; Chaki et al., 2009a, 2011a,b). Consequently, understanding if $S$-nitrosylation of PrxII E could be involved in plant response to these stress conditions is a good issue to be addressed in the future.

\section{NITRIC OXIDE INTERACTIONS WITH CATALASE AND SUPEROXIDE DISMUTASES}

Superoxide dismutase (SOD) is a group of metalloenzymes that catalyze the disproportionation of superoxide radicals into $\mathrm{H}_{2} \mathrm{O}_{2}$ (Fridovich, 1986; Halliwell and Gutteridge, 2000). SODs are classified into three main types containing $\mathrm{Mn}, \mathrm{Fe}$, or $\mathrm{Cu}$ plus $\mathrm{Zn}$ as prosthetic metals and they are present in all cell compartments (Parker et al., 1984; Zelko et al., 2002). In eukaryotic cells from different organisms, it has been demonstrated that $\mathrm{Mn}-$, Fe-, and $\mathrm{CuZn-SODs} \mathrm{undergo} \mathrm{inactivation} \mathrm{by} \mathrm{peroxynitrite-mediated}$ nitration (Demicheli et al., 2007; Martinez et al., 2014) and SOD activity is increased after GSNO treatment (Sehrawat et al., 2013). Recently, in vitro approaches have been used to analyze the 
effect of NO-mediated PTMs on the different SOD isozymes in Arabidopsis thaliana. Thus, whereas S-nitrosylation did not affect SOD activities, nitration inhibited Mn-SOD1, Fe-SOD3, and CuZn-SOD3 activity to different degrees but affected no other SOD isozymes (Holzmeister et al., 2015).

On the other hand, catalase, which is a peroxisomal key enzyme that regulates $\mathrm{H}_{2} \mathrm{O}_{2}$ levels (Chance et al., 1979; Kirkman and Gaetani, 1984), was one of the first antioxidant enzymes to be analyzed in vitro to check how its activity can be modulated by NO donors (Clark et al., 2000). At present, it is known that plant catalase can be nitrated and $S$-nitrosylated in vitro, both of which inhibit its activity (Clark et al., 2000; OrtegaGalisteo et al., 2012), although, according to the literature available, the specific target residues have not yet been identified. Very recently, it has been determined by proteomic approaches that catalase undergoes increasing nitration during pepper fruit maturation, decreasing its activity as consequence of potential tyrosine nitration as corroborated after treatment with SIN-1 (a peroxynitrite donor; Chaki et al., 2015). This inhibition could imply a lower capacity for removing $\mathrm{H}_{2} \mathrm{O}_{2}$ and therefore is well correlated with the increase of the oxidative metabolism observed during this physiological process (Martí et al., 2011; Chaki et al., 2015).

\section{ASCORBATE-GLUTATHIONE CYCLE AND NITRIC OXIDE-PTMS}

Ascorbate-glutathione cycle is a pivotal antioxidant system involved in the regulation of $\mathrm{H}_{2} \mathrm{O}_{2}$ levels (Asada, 1992; Noctor and Foyer, 1998; Shigeoka et al., 2002) under development and unfavorable conditions in plant cells. The cycle is composed of the enzymes APX, MDAR, DHAR, and GR plus the non-enzymatic antioxidants ascorbate and glutathione (GSH). Concomitant to $\mathrm{H}_{2} \mathrm{O}_{2}$ reduction to water, APX catalyzes the oxidation of ascorbate to monodehydroascorbate (MDA) which can spontaneously generate dehydroascorbate (DHA). Ascorbate is regenerated by MDAR and DHAR using NADPH and GSH as electron donors, respectively. Finally, GR is involved in regenerating GSH levels.

Analyzing how NO regulates Asa-GSH cycle is a key issue to understand the interplay between NO and antioxidant systems (Figure 1). In this sense, enzymatic activity of the components of Asa-GSH cycle can be modulated by NO and under different stress situations (Gro $\beta$ et al., 2013). Additionally, these enzymes have been identified as targets of NO-PTMs, identifying in some cases the molecular mechanism involved in these modifications (Table 1).

\section{Regulation of Asa-GSH Cycle by Tyrosine Nitration}

Proteomic approaches have identified all enzymes of the AsaGSH cycle as potential nitrated proteins (Chaki et al., 2009b; Lin et al., 2012; Tanou et al., 2012). However, information related to the specific impact of this modification on the structure of these target proteins and the role of the tyrosine target of nitration is necessary in order to understand the cross-talk between NO and ROS in the antioxidant defense against nitrosative stress. In this respect, two recent studies have identified the tyrosine target(s) of nitration and its (their) potential role within the mechanistic activity of the Asa-GSH cycle enzymes, showing that this NOPTM could compromise the Asa-GSH cycle functioning (BegaraMorales et al., 2014, 2015). Pea cytosolic APX is inactivated by $\mathrm{ONOO}^{-}$as consequence of tyrosine nitration (Begara-Morales et al., 2014) and as result the detoxification of $\mathrm{H}_{2} \mathrm{O}_{2}$ by AsaGSH cycle could be compromised (Figure 1). Proteomics and in

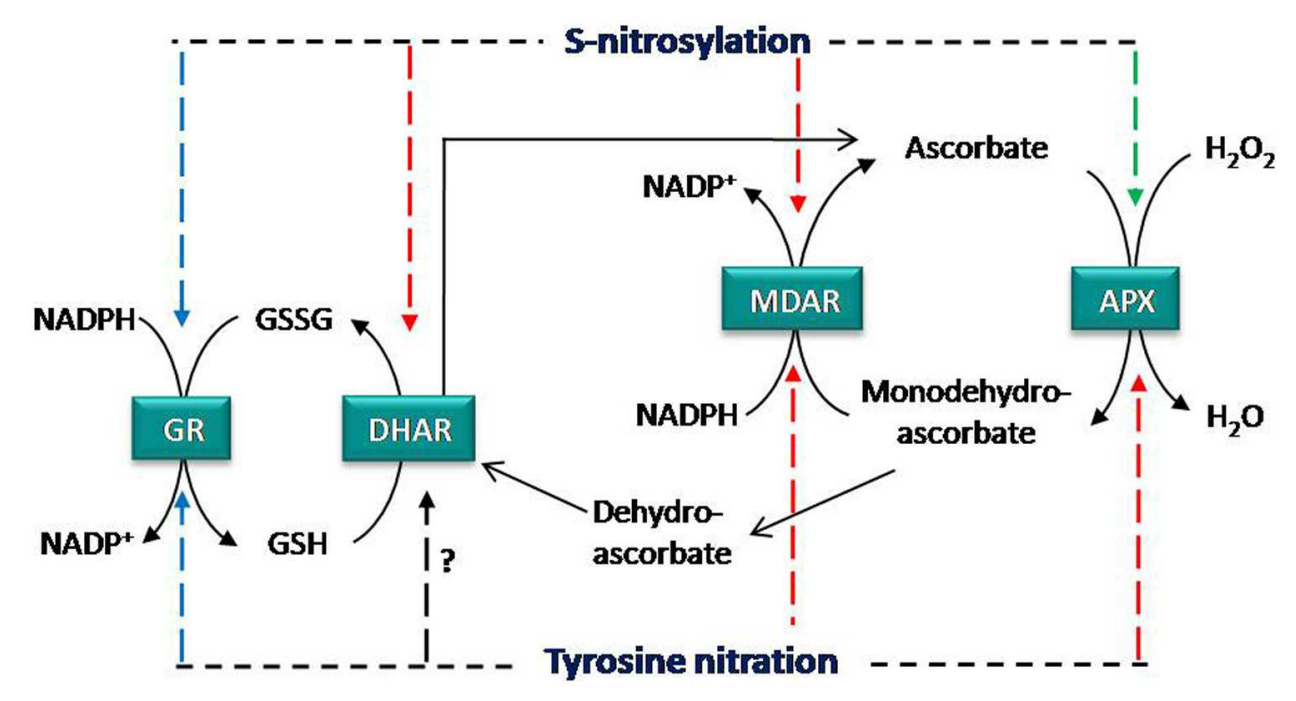

FIGURE 1 | Regulation of ascorbate glutathione cycle by NO-PTMs. APX activity is inhibited by tyrosine nitration and enhanced by S-nitrosylation, whereas MDAR is inhibited by both NO-PTMs. DHAR is inhibited by $S$-nitrosylation and GR is not affected by these PTMs. Color of arrows shows the effect of tyrosine nitration and S-nitrosylation on enzymatic activities; red: inhibition, green: enhancement, and blue: no effect. APX, ascorbate peroxidase; MDAR, monodehydroascrobate reductase; DHAR, dehydroascorbate reductase; GR, glutathione reductase. 
TABLE 1 | Effect of NO-PTMs on components of Asa-GSH cycle.

\begin{tabular}{|c|c|c|c|c|c|}
\hline Protein & NO-PTM & Effects & Target & Plant species & Reference \\
\hline Ascorbate peroxidase (APX) & $\begin{array}{l}\text { Tyrosine nitration } \\
\text { S-nitrosylation }\end{array}$ & $\begin{array}{l}\text { Decreased activity } \\
\text { Increased activity }\end{array}$ & $\begin{array}{l}\text { Tyr235(1) } \\
\text { Cys32(1)(2)(3) }\end{array}$ & $\begin{array}{l}\text { Pisum sativum } \\
\text { Arabidopsis thaliana, } \\
\text { Pisum sativum }\end{array}$ & $\begin{array}{l}\text { Begara-Morales et al., } 2014 \\
\text { Begara-Morales et al., 2014; } \\
\text { Yang et al., } 2015\end{array}$ \\
\hline $\begin{array}{l}\text { Monodehydro-ascorbate } \\
\text { reductase (MDAR) }\end{array}$ & $\begin{array}{l}\text { Tyrosine nitration } \\
\text { S-nitrosylation }\end{array}$ & $\begin{array}{l}\text { Decreased activity } \\
\text { Decreased activity }\end{array}$ & $\begin{array}{l}\text { Tyr345(1) } \\
\text { Cys68 }\end{array}$ & $\begin{array}{l}\text { Pisum sativum } \\
\text { Pisum sativum }\end{array}$ & $\begin{array}{l}\text { Begara-Morales et al., } 2015 \\
\text { Begara-Morales et al., } 2015\end{array}$ \\
\hline $\begin{array}{l}\text { Dehydro-ascorbate } \\
\text { reductase (DHAR) }\end{array}$ & $\begin{array}{l}\text { Tyrosine nitration } \\
\text { S-nitrosylation }\end{array}$ & $\begin{array}{l}\text { N.D. } \\
\text { Decreased activity }\end{array}$ & $\begin{array}{l}\text { N.D. } \\
\text { Cys20(1)(2), } \\
\text { Cys } 147^{(1)(2)}\end{array}$ & $\begin{array}{l}\text { N.D. } \\
\text { Arabidopsis thaliana; } \\
\text { Solanum tuberosum }\end{array}$ & $\begin{array}{l}\text { Fares et al., 2011; Kato et al., } \\
\text { 2013; Puyaubert et al., } 2014\end{array}$ \\
\hline Glutathione reductase (GR) & $\begin{array}{l}\text { Tyrosine nitration } \\
\text { S-nitrosylation }\end{array}$ & No effect & N.D. & Pisum sativum & Begara-Morales et al., 2015 \\
\hline
\end{tabular}

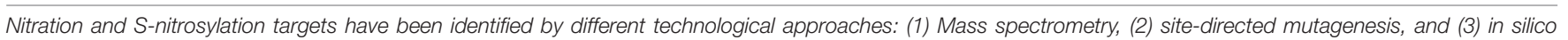
identification. ND: Not determined.

silico approaches identified the Tyr235 as the most reliable target responsible for APX inactivation, since this residue is located just at $3.6 \AA$ from the heme group at the bottom of the catalytic pocket (Patterson and Poulos, 1995; Jespersen et al., 1997; Mandelman et al., 1998; Begara-Morales et al., 2014). Consequently, Tyr235 nitration may disrupt heme-group properties and result in a loss of activity (Begara-Morales et al., 2014).

Monodehydroascorbate reductase, which is involved in the regeneration of ascorbate (Figure 1), is another significant modulation point of the Asa-GSH cycle. In this case, $\mathrm{ONOO}^{-}$ mediates nitration of recombinant pea MDAR at Tyr213, Tyr292, and Tyr345, causing an inhibition of the enzymatic activity (Begara-Morales et al., 2015), and therefore may disrupt the regeneration of ascorbate and compromise the functioning of the Asa-GSH cycle. Site-directed mutagenesis demonstrates that Tyr345 is the main residue responsible for the loss of activity after nitration, since this tyrosine is located just at $3.3 \AA$ from His313, which is involved in NADP binding, suggesting that the nitration of this tyrosine could alter the positioning of the cofactor, thereby decreasing protein activity (Begara-Morales et al., 2015). DHAR is the other enzyme involved in the regeneration of ascorbate, but, although DHAR has been reported to be nitrated (Tanou et al., 2012) and its activity modulated by NO (see Gro $\beta$ et al., 2013), no information is available on the tyrosine(s) involved in this modification and the impact on the protein structure.

Glutathione reductase has also been identified as tyrosine nitration target (Chaki et al., 2009b). In animals, peroxynitrite inhibits human and bovine GR activity by nitration of Tyr106 and Tyr114 which are located close to the GSSG binding zone (Francescutti et al., 1996; Savvides et al., 2002). However, very recently and in contrast to animals, it has been strikingly shown that chloroplastic and cytosolic pea GR activities are not affected by peroxynitrite-mediated tyrosine nitration (Begara-Morales et al., 2015). This behavior is unusual in higher plants, where the main effect of tyrosine nitration on target proteins is usually a loss of function (Astier and Lindermayr, 2012; Begara-Morales et al., 2013; Chaki et al., 2013; Corpas et al., 2013).

\section{S-Nitrosylation on Asa-GSH Cycle}

$S$-nitrosylation has emerged as a key PTM that regulates fundamental processes in plant biology such as plant immunity or plant response to (a)biotic stress. Consequently, this PTM has become the main pathway by which $\mathrm{NO}$ acts as a signaling molecule. Hundreds of proteins related to a wide range of metabolic pathways have been reported to be $S$-nitrosylated in plants. For instance, NO regulates many enzymes involved in ROS/RNS generation/scavenging such as GSNOR (Frungillo et al., 2014), NADPH oxidase (Yun et al., 2011), catalase (OrtegaGalisteo et al., 2012), and peroxiredoxinII E (Romero-Puertas et al., 2007) and II F (Camejo et al., 2015). S-nitrosylation appears to be critical to $\mathrm{GSNO}$ and $\mathrm{ONOO}^{-}$homeostasis as this NO-PTM inhibits GSNOR and PrxII E activities (RomeroPuertas et al., 2007; Frungillo et al., 2014) that decompose GSNO and $\mathrm{ONOO}^{-}$, respectively. Consequently, during a nitro-oxidative stress the inactivation of these enzymes by $S$ nitrosylation could favor the accumulation of these NO-derived molecules that in turn may increase the effects of the generated stress.

A connection has also been observed between NO and ROS pathway under different physiological and stress conditions (Corpas et al., 2011; Gro $\beta$ et al., 2013; Procházková et al., 2014). Furthermore, all components of Asa-GSH cycle have been reported to be $S$-nitrosylated (Lin et al., 2012; Tanou et al., 2012) with a different effect on protein activity (Kato et al., 2013; Begara-Morales et al., 2014, 2015).

Dehydroascorbate reductase has been identified as $S$ nitrosylation target at Cys20 under no-stress conditions in Arabidopsis, and this Cys20 is not over-nitrosylated under salinity or cold stress (Fares et al., 2011; Puyaubert et al., 2014). Recently, it has been reported that $S$-nitrosylation at Cys20 and Cys147 negatively regulates the enzymatic activity of DHAR in potato plants (Kato et al., 2013). Furthermore, peroxisomal recombinant pea MDAR, which has only two cysteines (Cys197 and Cys68) is also inhibited by $S$-nitrosylation (Begara-Morales et al., 2015). The authors suggest using in silico and evolutionary analysis that Cys68 could be the most reliable residue responsible for the loss of activity following GSNO treatment. However, future experiments such as site-directed mutagenesis and/or mass spectrometry are needed to verify this postulation. In any case, it is clear that peroxisomal pea MDAR is $S$-nitrosylated by GSNO, as corroborated by the biotin-switch method, and as result the protein activity is inhibited 
(Begara-Morales et al., 2015). The inhibition of DHAR and MDAR by $S$-nitrosylation (Figure 1) could compromise ascorbate regeneration and therefore the functioning of the cycle. Notably, in the same work it is shown that chloroplastic and cytosolic pea GR are also $S$-nitrosylated by GSNO. However, this modification does not significantly affect protein activity, as happens after tyrosine nitration (see above). In mammal cells GSNO treatment for $1 \mathrm{~h}$ does not affect GR, although an inhibitory effect is produced after longer exposures to GSNO (Beltrán et al., 2000). In addition, human GR is inhibited by GSNO as consequence of $S$-nitrosylation of two catalytic Cys, Cys63 and/or Cys58 (Becker et al., 1995; Francescutti et al., 1996). These results suggest a different regulation of pea and mammalian GR since that pea GR activity could be unaffected by any NO-PTMs under a nitro-oxidative stress situation (BegaraMorales et al., 2015) in an attempt to maintain GSH levels and consequently the cellular redox state.

Regarding the regulation of Asa-GSH cycle by $S$-nitrosylation, the best characterized enzyme is APX. APX $S$-nitrosylation could have an essential role in physiological and stress conditions via regulation of APX activity (Correa-Aragunde et al., 2013; de Pinto et al., 2013; Begara-Morales et al., 2014), highlighting that APX can constitute a critical interface in the relationship between $\mathrm{NO}$ and $\mathrm{H}_{2} \mathrm{O}_{2}$ metabolism (Lindermayr and Durner, 2015). It has been suggested that Arabidopsis APX $S$-nitrosylation/denitrosylation mediated by auxins could be involved in the determination of root architecture (CorreaAragunde et al., 2013, 2015). In this situation, APX1 is $S$-nitrosylated in vivo and auxins-mediated denitrosylation decreased the protein activity, an effect corroborated by the treatment of APX1 recombinant protein with CysNO (CorreaAragunde et al., 2013). In contrast, de Pinto et al. (2013) reported that APX S-nitrosylation mediated by GSNO inhibits protein activity in tobacco plants and that this change could be related to programmed cell death (PCD). By in silico analysis, in the former study is postulated that the increase in APX activity is consequence of $S$-nitrosylation at Cys168, whereas in the latter it is suggested that the inactivation is due to $S$-nitrosylation at Cys32. However, Clark et al. (2000) reported that the inactivation of tobacco APX activity by GSNO could be due to the formation of an iron-nitrosyl complex between NO and the heme group's iron atom. This implies that, Cys168, which is located near heme group, could be the responsible for APX activity inactivation, and not Cys32. In this sense, further experimental data (e.g., site-directed mutagenesis) could be needed to confirm what Cys is(are) involved in the (de)activation of the protein activity.

Another study described an increase in S-nitrosylation of pea APX as a protective mechanism in response to salinity stress (Begara-Morales et al., 2014). In this case, the cytosolic pea APX activity is stimulated by $S$-nitrosylation in vitro and in vivo. The advantage of this work is that the sequence of pea APX contains only one Cys32, making this residue the only candidate to be
$S$-nitrosylated and responsible for increasing APX activity after $S$-nitrosylation. This finding has been recently corroborated by Yang et al. (2015), who showed using proteomic and mutagenesis approaches that $S$-nitrosylation at Cys32 positively regulates APX1 activity in Arabidopsis. In addition, they demonstrated that $S$-nitrosylation of Cys32 plays an essential role in plant response to oxidative stress and in plant immunity. As result, $S$ nitrosylation of Cys32 appears to be responsible for increasing activity of APX (Figure 1).

\section{CONCLUSION AND FUTURE PERSPECTIVES}

Nitric oxide and $\mathrm{H}_{2} \mathrm{O}_{2}$ are essential signaling molecules involved in physiological processes and plant response to unfavorable conditions. These molecules share signaling pathways, so that it is not surprising to find cross-talk by which one pathway can control the function of the other. In this regard, key control points of ROS metabolism by NO are the PTMs of catalase, SODs, peroxiredoxins, and enzymes of the Asa-GSH cycle. Recent findings indicate that the antioxidant capacity of AsaGSH cycle could be compromised under stress situations that generate nitro-oxidative stress, due to the inactivation of APX and MDAR activities by tyrosine nitration (Figure 1). However, APX activity is increased by $S$-nitrosylation while GR is not affected by these NO-PTMs, suggesting that GR tries to maintain GSH regeneration and therefore the cellular redox state in order to sustain the Asa-GSH cycle's resistance to nitro-oxidative cell conditions. It bears noting that APX is under dual regulation by tyrosine nitration and $S$-nitrosylation, which are two different oxidative states related to nitro-oxidative stress. In this sense, future research should delve into the regulation of Asa-GSH cycle according to the oxidative stress generated and affected cell compartments.

\section{AUTHOR CONTRIBUTIONS}

The experiments were conceived and designed by: JB, FC, and JB-M. The experiments were performed by: JB-M, BS-C, MC, RV, CM-P, and MP. The data were analyzed by: JB, FC, and JB-M. The paper was written by: JB-M and JB.

\section{ACKNOWLEDGMENTS}

JB-M would like to thank the Ministry of Science and Innovation for funding the Ph.D. fellowship (F.P.U.). This study was supported by an ERDF grant co-financed by the Ministry of Economy and Competitiveness (project BIO2012-33904), Junta de Andalucía (P10-AGR-6038 and groups BIO286 and BIO192) and RECUPERA2020 in Spain. 


\section{REFERENCES}

Abello, N., Kerstjens, H. A. M., Postma, D. S., and Bischoff, R. (2009). Protein tyrosine nitration: selectivity, physicochemical and biological consequences, denitration, and proteomics methods for the identification of tyrosine-nitrated proteins. J. Proteome Res. 8, 3222-3238. doi: 10.1021/pr900039c

Asada, K. (1992). Ascorbate peroxidase: a hydrogen peroxide-scavenging enzyme in plants. Physiol. Plant. 85, 235-241. doi: 10.1111/j.1399-3054.1992. tb04728.x

Astier, J., and Lindermayr, C. (2012). Nitric oxide-dependent posttranslational modification in plants: an update. Int. J. Mol. Sci. 13, 15193-15208. doi: 10.3390/ijms131115193

Astier, J., Rasul, S., Koen, E., Manzoor, H., Besson-Bard, A., Lamotte, O., et al. (2011). S-nitrosylation: an emerging post-translational protein modification in plants. Plant Sci. 181, 527-533. doi: 10.1016/j.plantsci.2011.02.011

Becker, K., Gui, M., and Schirmer, R. H. (1995). Inhibition of human glutathione reductase by S-nitrosoglutathione. Eur. J. Biochem. 234, 472-478. doi: 10.1111/j.1432-1033.1995.472_b.x

Begara-Morales, J. C., Chaki, M., Sánchez-Calvo, B., Mata-Pérez, C., Leterrier, M., Palma, J. M., et al. (2013). Protein tyrosine nitration in pea roots during development and senescence. J. Exp. Bot. 64, 1121-1134. doi: $10.1093 / \mathrm{jxb} / \mathrm{ert006}$

Begara-Morales, J. C., Sánchez-Calvo, B., Chaki, M., Mata-Pérez, C., Valderrama, R., Padilla, M. N., et al. (2015). Differential molecular response of monodehydroascorbate reductase and glutathione reductase by nitration and S-nitrosylation. J. Exp. Bot. 66, 5983-5996. doi: 10.1093/jxb/erv306

Begara-Morales, J. C., Sánchez-Calvo, B., Chaki, M., Valderrama, R., MataPérez, C., López-Jaramillo, J., et al. (2014). Dual regulation of cytosolic ascorbate peroxidase (APX) by tyrosine nitration and S-nitrosylation. J. Exp. Bot. 65, 527-538. doi: $10.1093 / \mathrm{jxb} / \mathrm{ert} 396$

Belenghi, B., Romero-Puertas, M. C., Vercammen, D., Brackenier, A., Inzé, D., Delledonne, M., et al. (2007). Metacaspase activity of Arabidopsis thaliana is regulated by S-nitrosylation of a critical cysteine residue. J. Biol. Chem. 282, 1352-1358. doi: 10.1074/jbc.M608931200

Beligni, M. V., and Lamattina, L. (2000). Nitric oxide stimulates seed germination and de-etiolation, and inhibits hypocotyl elongation, three light-inducible responses in plants. Planta 210, 215-221. doi: 10.1007/PL00008128

Beltrán, B., Orsi, A., Clementi, E., and Moncada, S. (2000). Oxidative stress and S-nitrosylation of proteins in cells. Br. J. Pharmacol. 129, 953-960. doi: 10.1038/sj.bjp.0703147

Benhar, M., Forrester, M. T., Hess, D. T., and Stamler, J. S. (2008). Regulated protein denitrosylation by cytosolic and mitochondrial thioredoxins. Science 320, 1050-1054. doi: 10.1126/science. 1158265

Bhatt, I., and Tripathi, B. N. (2011). Plant peroxiredoxins: catalytic mechanisms, functional significance and future perspectives. Biotechnol. Adv. 29, 850-859. doi: 10.1016/j.biotechadv.2011.07.002

Bryk, R., Griffin, P., and Nathan, C. (2000). Peroxynitrite reductase activity of bacterial peroxiredoxins. Nature 407, 211-215. doi: 10.1038/35025109

Camejo, D., Ortiz-Espín, A., Lázaro, J. J., Romero-Puertas, M. C., LázaroPayo, A., Sevilla, F., et al. (2015). Functional and structural changes in plant mitochondrial PrxII F caused by NO. J. Proteomics 119, 112-125. doi: 10.1016/j.jprot.2015.01.022

Chaki, M., Carreras, A., López-Jaramillo, J., Begara-Morales, J. C., SánchezCalvo, B., Valderrama, R., et al. (2013). Tyrosine nitration provokes inhibition of sunflower carbonic anhydrase $(\beta-\mathrm{CA})$ activity under high temperature stress. Nitric Oxide 29, 30-33. doi: 10.1016/j.niox.2012.12.003

Chaki, M., de Morales, P. Á., Ruiz, C., Begara-Morales, J. C., Barroso, J. B., Corpas, F. J., et al. (2015). Ripening of pepper (Capsicum annuum) fruit is characterized by an enhancement of protein tyrosine nitration. Ann. Bot. 116, 637-647. doi: $10.1093 / \mathrm{aob} / \mathrm{mcv} 016$

Chaki, M., Fernández-Ocaña, A. M., Valderrama, R., Carreras, A., Esteban, F. J., Luque, F., et al. (2009a). Involvement of reactive nitrogen and oxygen species (RNS and ROS) in sunflower-mildew interaction. Plant Cell Physiol. 50, 265279. doi: $10.1093 / \mathrm{pcp} / \mathrm{pcn} 196$

Chaki, M., Valderrama, R., Fernández-Ocaña, A. M., Carreras, A., LópezJaramillo, J., Luque, F., et al. (2009b). Protein targets of tyrosine nitration in sunflower (Helianthus annuus L.) hypocotyls. J. Exp. Bot. 60, 4221-4234. doi: $10.1093 / \mathrm{jxb} / \mathrm{erp} 263$
Chaki, M., Valderrama, R., Fernández-Ocaña, A. M., Carreras, A., GómezRodíguez, M. V., Pedrajas, J. R., et al. (2011a). Mechanical wounding induces a nitrosative stress by down-regulation of GSNO reductase and an increase in S-nitrosothiols in sunflower (Helianthus annuus) seedlings. J. Exp. Bot. 62, 1803-1813. doi: 10.1093/jxb/erq358

Chaki, M., Valderrama, R., Fernández-Ocaña, A. M., Carreras, A., GómezRodríguez, M. V., López-Jaramillo, J., et al. (2011b). High temperature triggers the metabolism of S-nitrosothiols in sunflower mediating a process of nitrosative stress which provokes the inhibition of ferredoxin-NADP reductase by tyrosine nitration. Plant Cell Environ. 34, 1803-1818. doi: 10.1111/j.13653040.2011.02376.x

Chance, B., Sies, H., and Boveris, A. (1979). Hydroperoxide metabolism in mammalian organs. Physiol. Rev. 59, 527-605.

Clark, D., Durner, J., Navarre, D. A., and Klessig, D. F. (2000). Nitric oxide inhibition of tobacco catalase and ascorbate peroxidase. Mol. Plant Microbe Interact. 13, 1380-1384. doi: 10.1094/MPMI.2000.13.12.1380

Corpas, F. J., Begara-Morales, J. C., Sánchez-Calvo, B., Chaki, M., and Barroso, J. B. (2015). "Nitration and S-Nitrosylation: two post-translational modifications (PTMs) mediated by reactive nitrogen species (RNS) and their role in signalling processes of plant cells," in Reactive Oxygen and Nitrogen Species Signaling and Communication in Plants, eds K. J. Gupta and A. U. Igamberdiev (Berlin: Springer), 267-281.

Corpas, F. J., Chaki, M., Fernández-Ocaña, A., Valderrama, R., Palma, J. M., Carreras, A., et al. (2008). Metabolism of reactive nitrogen species in pea plants under abiotic stress conditions. Plant Cell Physiol. 49, 1711-1722. doi: 10.1093/pcp/pcn144

Corpas, F. J., Leterrier, M., Begara-Morales, J. C., Valderrama, R., Chaki, M., LópezJaramillo, J., et al. (2013). Inhibition of peroxisomal hydroxypyruvate reductase (HPR1) by tyrosine nitration. Biochim. Biophys. Acta 1830, 4981-4989. doi: 10.1016/j.bbagen.2013.07.002

Corpas, F. J., Leterrier, M., Valderrama, R., Airaki, M., Chaki, M., Palma, J. M., et al. (2011). Nitric oxide imbalance provokes a nitrosative response in plants under abiotic stress. Plant Sci. 181, 604-611. doi: 10.1016/j.plantsci.2011. 04.005

Correa-Aragunde, N., Cejudo, F. J., and Lamattina, L. (2015). Nitric oxide is required for the auxin-induced activation of NADPH-dependent thioredoxin reductase and protein denitrosylation during root growth responses in arabidopsis. Ann. Bot. 116, 695-702. doi: 10.1093/aob/mcv116

Correa-Aragunde, N., Foresi, N., Delledonne, M., and Lamattina, L. (2013). Auxin induces redox regulation of ascorbate peroxidase 1 activity by S-nitrosylation/denitrosylation balance resulting in changes of root growth pattern in Arabidopsis. J. Exp. Bot. 64, 3339-3349. doi: 10.1093/jxb/ ert172

de Pinto, M. C., Locato, V., Sgobba, A., Romero-Puertas, M., Gadaleta, C., Delledonne, M., et al. (2013). S-nitrosylation of ascorbate peroxidase is part of programmed cell death signaling in tobacco Bright Yellow-2 cells. Plant Physiol. 163, 1766-1775. doi: 10.1104/pp.113.222703

Deeb, R. S., Nuriel, T., Cheung, C., Summers, B., Lamon, B. D., Gross, S. S., et al. (2013). Characterization of a cellular denitrase activity that reverses nitration of cyclooxygenase. Am. J. Physiol. Heart Circ. Physiol. 305, H687-H698. doi: 10.1152/ajpheart.00876.2012

Delledonne, M., Xia, Y., Dixon, R. A., and Lamb, C. (1998). Nitric oxide functions as a signal in plant disease resistance. Nature 394, 585-588. doi: 10.1038/29087

Demicheli, V., Quijano, C., Alvarez, B., and Radi, R. (2007). Inactivation and nitration of human superoxide dismutase (SOD) by fluxes of nitric oxide and superoxide. Free Radic. Biol. Med. 42, 1359-1368. doi: 10.1016/j.freeradbiomed.2007.01.034

Durner, J., Gow, A. J., Stamler, J. S., and Glazebrook, J. (1999). Ancient origins of nitric oxide signaling in biological systems. Proc. Natl. Acad. Sci. U.S.A. 96, 14206-14207. doi: 10.1073/pnas.96.25.14206

Durner, J., Wendehenne, D., and Klessig, D. F. (1998). Defense gene induction in tobacco by nitric oxide, cyclic GMP, and cyclic ADP-ribose. Proc. Natl. Acad. Sci. U.S.A. 95, 10328-10333. doi: 10.1073/pnas.95.17.10328

Engelman, R., Weisman-Shomer, P., Ziv, T., Xu, J., Arnér, E. S. J., and Benhar, M. (2013). Multilevel regulation of 2-Cys peroxiredoxin reaction cycle by S-nitrosylation. J. Biol. Chem. 288, 11312-11324. doi: 10.1074/jbc.M112.433755 Fang, J., Nakamura, T., Cho, D. H., Gu, Z., and Lipton, S. A. (2007). S-nitrosylation of peroxiredoxin 2 promotes oxidative stress-induced neuronal cell death 
in Parkinson's disease. Proc. Natl. Acad. Sci. U.S.A 104, 18742-18747. doi: 10.1073/pnas.0705904104

Fares, A., Rossignol, M., and Peltier, J. B. (2011). Proteomics investigation of endogenous S-nitrosylation in Arabidopsis. Biochem. Biophys. Res. Commun. 416, 331-336. doi: 10.1016/j.bbrc.2011.11.036

Feechan, A., Kwon, E., Yun, B.-W., Wang, Y., Pallas, J. A., and Loake, G. J. (2005). A central role for S-nitrosothiols in plant disease resistance. Proc. Natl. Acad. Sci. U.S.A. 102, 8054-8059. doi: 10.1073/pnas.0501456102

Francescutti, D., Baldwin, J., Lee, L., and Mutus, B. (1996). Peroxynitrite modification of glutathione reductase: modeling studies and kinetic evidence suggest the modification of tyrosines at the glutathione disulfide binding site. Protein Eng. 9, 189-194. doi: 10.1093/protein/9.2.189

Fridovich, I. (1986). Biological effects of the superoxide radical. Arch. Biochem. Biophys. 247, 1-11. doi: 10.1016/0003-9861(86)90526-6

Frungillo, L., Skelly, M. J., Loake, G. J., Spoel, S. H., and Salgado, I. (2014). S-nitrosothiols regulate nitric oxide production and storage in plants through the nitrogen assimilation pathway. Nat. Commun. 5:5401. doi: $10.1038 /$ ncomms6401

Gaston, B., Reilly, J., Drazen, J. M., Fackler, J., Ramdev, P., Arnelle, D., et al. (1993). Endogenous nitrogen oxides and bronchodilator S-nitrosothiols in human airways. Proc. Natl. Acad. Sci. U.S.A. 90, 10957-10961. doi: 10.1073/pnas.90.23.10957

Görg, B., Qvartskhava, N., Voss, P., Grune, T., Häussinger, D., and Schliess, F. (2007). Reversible inhibition of mammalian glutamine synthetase by tyrosine nitration. FEBS Lett. 581, 84-90. doi: 10.1016/j.febslet.2006.11.081

Gow, A. J., Farkouh, C. R., Munson, D. A., Posencheg, M. A., and Ischiropoulos, H. (2004). Biological significance of nitric oxide-mediated protein modifications. Am. J. Physiol. Lung Cell. Mol. Physiol. 287, L262-L268. doi: 10.1152/ajplung.00295.2003

Groß, F., Durner, J., and Gaupels, F. (2013). Nitric oxide, antioxidants and prooxidants in plant defence responses. Front. Plant Sci. 4:419. doi: 10.3389/fpls.2013.00419

Halliwell, B., and Gutteridge, J. M. C. (2000). Free Radicals in Biology and Medicine. London: Oxford University Press.

Hess, D. T., Matsumoto, A., Kim, S.-O., Marshall, H. E., and Stamler, J. S. (2005). Protein S-nitrosylation: purview and parameters. Nat. Rev. Mol. Cell Biol. 6, 150-166. doi: 10.1038/nrm1569

Holzmeister, C., Gaupels, F., Geerlof, A., Sarioglu, H., Sattler, M., Durner, J., et al. (2015). Differential inhibition of Arabidopsis superoxide dismutases by peroxynitrite-mediated tyrosine nitration. J. Exp. Bot. 66, 989-999. doi: $10.1093 / \mathrm{jxb} / \mathrm{eru} 458$

Hu, J., Huang, X., Chen, L., Sun, X., Lu, C., Zhang, L., et al. (2015). Site-specific nitrosoproteomic identification of endogenously S-nitrosylated proteins in Arabidopsis. Plant Physiol. 167, 1731-1746. doi: 10.1104/pp.15.00026

Jespersen, H., Kjrd, I., Stergaard, L., and Welinder, K. (1997). From sequence analysis of three novel ascorbate peroxidases from Arabidopsis thaliana to structure, function and evolution of seven types of ascorbate peroxidase. Biochem. J. 326, 305-310. doi: 10.1042/bj3260305

Kato, H., Takemoto, D., and Kawakita, K. (2013). Proteomic analysis of S-nitrosylated proteins in potato plant. Physiol. Plant. 148, 371-386. doi: $10.1111 /$ j.1399-3054.2012.01684.x

Kirkman, H. N., and Gaetani, G. F. (1984). Catalase: a tetrameric enzyme with four tightly bound molecules of NADPH. Proc. Natl. Acad. Sci U.S.A. 81, 4343-4347. doi: $10.1073 /$ pnas.81.14.4343

Kneeshaw, S., Gelineau, S., Tada, Y., Loake, G. J., and Spoel, S. H. (2014). Selective protein denitrosylation activity of thioredoxin-h5 modulates plant immunity. Mol. Cell 56, 153-162. doi: 10.1016/j.molcel.2014.08.003

Leitner, M., Vandelle, E., Gaupels, F., Bellin, D., and Delledonne, M. (2009). NO signals in the haze: nitric oxide signalling in plant defence. Curr. Opin. Plant Biol. 12, 451-458. doi: 10.1016/j.pbi.2009.05.012

Lin, A., Wang, Y., Tang, J., Xue, P., Li, C., Liu, L., et al. (2012). Nitric oxide and protein S-nitrosylation are integral to hydrogen peroxide-induced leaf cell death in rice. Plant Physiol. 158, 451-464. doi: 10.1104/pp.111.184531

Lindermayr, C., and Durner, J. (2009). S-Nitrosylation in plants: pattern and function. J. Proteomics 73, 1-9. doi: 10.1016/j.jprot.2009.07.002

Lindermayr, C., and Durner, J. (2015). Interplay of reactive oxygen species and nitric oxide: nitric oxide coordinates reactive oxygen species homeostasis. Plant Physiol. 167, 1209-1210. doi: 10.1104/pp.15.00293
Liu, L., Hausladen, A., Zeng, M., Que, L., Heitman, J., and Stamler, J. S. (2001). A metabolic enzyme for S-nitrosothiol conserved from bacteria to humans. Nature 410, 490-494. doi: 10.1038/35068596

Mandelman, D., Jamal, J., and Poulos, T. L. (1998). Identification of two electron-transfer sites in ascorbate peroxidase using chemical modification, enzyme kinetics, and crystallography. Biochemistry 37, 17610-17617. doi: 10.1021/bi981958y

Martí, M. C., Camejo, D., Vallejo, F., Romojaro, F., Bacarizo, S., Palma, J. M., et al. (2011). Influence of fruit ripening stage and harvest period on the antioxidant content of sweet pepper cultivars. Plant Foods Hum. Nutr. 66, 416-423. doi: 10.1007/s11130-011-0249-x

Martinez, A., Peluffo, G., Petruk, A. A., Hugo, M., Piñeyro, D., Demicheli, V., et al. (2014). Structural and Molecular Basis of the Peroxynitrite-mediated Nitration and Inactivation of Trypanosoma cruzi Iron-Superoxide Dismutases (Fe-SODs) A and B: disparate susceptibilities due to the repair of Tyr35 radical by Cys83 in Fe-SODB through intramolecular electron transfer. J. Biol. Chem. 289, 12760-12778. doi: 10.1074/jbc.M113.545590

Neill, S. J., Desikan, R., Clarke, A., Hurst, R. D., and Hancock, J. T. (2002). Hydrogen peroxide and nitric oxide as signalling molecules in plants. J. Exp. Bot. 53, 1237-1247. doi: 10.1093/jexbot/53.372.1237

Noctor, G., and Foyer, C. H. (1998). Ascorbate and glutathione: keeping active oxygen under control. Annu. Rev. Plant Physiol. Plant Mol. Biol. 49, 249-279. doi: 10.1146/annurev.arplant.49.1.249

Ortega-Galisteo, A. P., Rodríguez-Serrano, M., Pazmiño, D. M., Gupta, D. K., Sandalio, L. M., and Romero-Puertas, M. C. (2012). S-Nitrosylated proteins in pea (Pisum sativum L.) leaf peroxisomes: changes under abiotic stress. J. Exp. Bot. 63, 2089-2103. doi: 10.1093/jxb/err414

Pagnussat, G. C., Simontacchi, M., Puntarulo, S., and Lamattina, L. (2002). Nitric oxide is required for root organogenesis. Plant Physiol. 129, 954-956. doi: 10.1104/pp.004036

Parker, M. W., Schinina, M. E., Bossa, F., and Bannister, J. V. (1984). Chemical aspects of the structure, function and evolution of superoxide dismutases. Inog. Chim. Acta 91, 307-317. doi: 10.1016/S0020-1693(00)81854-X

Patterson, W. R., and Poulos, T. L. (1995). Crystal structure of recombinant pea cytosolic ascorbate peroxidase. Biochemistry 34, 4331-4341. doi: 10.1021/bi00013a023

Pedrajas, J. R., Carreras, A., Valderrama, R., and Barroso, J. B. (2010). Mitochondrial 1-Cys-peroxiredoxin/thioredoxin system protects manganesecontaining superoxide dismutase (Mn-SOD) against inactivation by peroxynitrite in Saccharomyces cerevisiae. Nitric Oxide 23, 206-213. doi: 10.1016/j.niox.2010.06.004

Procházková, D., Sumaira, J., Wilhelmová, N. A., Pavlíková, D., and Száková, J. (2014). "Reactive nitrogen species and the role of NO in abiotic stress," in Emerging Technologies and Managment of Crops Stress Tolerance, ed. P. Ahmad (Amsterdam: Elsevier).

Puyaubert, J., Fares, A., Rézé, N., Peltier, J.-B., and Baudouin, E. (2014). Identification of endogenously S-nitrosylated proteins in Arabidopsis plantlets: effect of cold stress on cysteine nitrosylation level. Plant Sci. 215, 150-156. doi: 10.1016/j.plantsci.2013.10.014

Radi, R. (2004). Nitric oxide, oxidants, and protein tyrosine nitration. Proc. Natl. Acad. Sci. U.S.A. 101, 4003-4008. doi: 10.1073/pnas.0307446101

Radi, R. (2013). Protein tyrosine nitration: biochemical mechanisms and structural basis of functional effects. Acc. Chem. Res. 46, 550-559. doi: 10.1021/ar30 $0234 \mathrm{c}$

Randall, L. M., Manta, B., Hugo, M., Gil, M., Batthyàny, C., Trujillo, M., et al. (2014). Nitration transforms a sensitive peroxiredoxin 2 into a more active and robust peroxidase. J. Biol. Chem. 289, 15536-15543. doi: 10.1074/jbc.M113.539213

Romero-Puertas, M. C., Campostrini, N., Mattè, A., Righetti, P. G., Perazzolli, M., Zolla, L., et al. (2008). Proteomic analysis of S-nitrosylated proteins in Arabidopsis thaliana undergoing hypersensitive response. Proteomics 8, 14591469. doi: 10.1002/pmic.200700536

Romero-Puertas, M. C., Laxa, M., Mattè, A., Zaninotto, F., Finkemeier, I., Jones, A. M. E., et al. (2007). S-nitrosylation of peroxiredoxin II E promotes peroxynitrite-mediated tyrosine nitration. Plant Cell 19, 4120-4130. doi: 10.1105/tpc.107.055061

Rusterucci, C., Espunya, M. C., Díaz, M., Chabannes, M., and Martínez, M. C. (2007). S-nitrosoglutathione reductase affords protection against pathogens in 
Arabidopsis, both locally and systemically. Plant Physiol. 143, 1282-1292. doi: 10.1104/pp.106.091686

Savvides, S. N., Scheiwein, M., Bohme, C. C., Arteel, G. E., Karplus, P. A., Becker, K., et al. (2002). Crystal structure of the antioxidant enzyme glutathione reductase inactivated by peroxynitrite. J. Biol. Chem. 277, 2779-2784. doi: 10.1074/jbc.M108190200

Sehrawat, A., Abat, J. K., and Deswal, R. (2013). RuBisCO depletion improved proteome coverage of cold responsive S-nitrosylated targets in Brassica juncea. Front. Plant Sci. 4:342. doi: 10.3389/fpls.2013.00342

Shigeoka, S., Ishikawa, T., Tamoi, M., Miyagawa, Y., Takeda, T., Yabuta, Y., et al. (2002). Regulation and function of ascorbate peroxidase isoenzymes. J. Exp. Bot. 53, 1305-1319. doi: 10.1093/jexbot/53.372.1305

Siddiqui, M. H., Al-Whaibi, M. H., and Basalah, M. O. (2011). Role of nitric oxide in tolerance of plants to abiotic stress. Protoplasma 248, 447-455. doi: 10.1007/s00709-010-0206-9

Souza, J. M., Peluffo, G., and Radi, R. (2008). Protein tyrosine nitration-functional alteration or just a biomarker? Free Radic. Biol. Med. 45, 357-366. doi: 10.1016/j.freeradbiomed.2008.04.010

Tanou, G., Filippou, P., Belghazi, M., Job, D., Diamantidis, G., Fotopoulos, V., et al. (2012). Oxidative and nitrosative-based signaling and associated post-translational modifications orchestrate the acclimation of citrus plants to salinity stress. Plant J. 72, 585-599. doi: 10.1111/j.1365-313X.2012. 05100.x

Turko, I. V., and Murad, F. (2002). Protein nitration in cardiovascular diseases. Pharmacol. Rev. 54, 619-634. doi: 10.1124/pr.54.4.619
Valderrama, R., Corpas, F. J., Carreras, A., Fernández-Ocaña, A., Chaki, M., Luque, F., et al. (2007). Nitrosative stress in plants. FEBS Lett. 581, 453-461. doi: 10.1016/j.febslet.2007.01.006

Yang, H., Mu, J., Chen, L., Feng, J., Hu, J., Li, L., et al. (2015). S-Nitrosylation positively regulates ascorbate peroxidase activity during plant stress responses. Plant Physiol. 167, 1604-1615. doi: 10.1104/pp.114.255216

Yun, B.-W., Feechan, A., Yin, M., Saidi, N. B. B., Le Bihan, T., Yu, M., et al. (2011). S-nitrosylation of NADPH oxidase regulates cell death in plant immunity. Nature 478, 264-268. doi: 10.1038/nature10427

Zelko, I. N., Mariani, T. J., and Folz, R. J. (2002). Superoxide dismutase multigene family: a comparison of the CuZn-SOD (SOD1), Mn-SOD (SOD2), and ECSOD (SOD3) gene structures, evolution, and expression Free Radic. Biol. Med. 33, 337-349. doi: 10.1016/S0891-5849(02)00905-X

Conflict of Interest Statement: The authors declare that the research was conducted in the absence of any commercial or financial relationships that could be construed as a potential conflict of interest.

Copyright $\odot 2016$ Begara-Morales, Sánchez-Calvo, Chaki, Valderrama, Mata-Pérez, Padilla, Corpas and Barroso. This is an open-access article distributed under the terms of the Creative Commons Attribution License (CC BY). The use, distribution or reproduction in other forums is permitted, provided the original author(s) or licensor are credited and that the original publication in this journal is cited, in accordance with accepted academic practice. No use, distribution or reproduction is permitted which does not comply with these terms. 